\title{
A ausência da música portuguesa no contexto europeu: Uma investigação em curso
}

The Absence of Portuguese Music in the European Context: an Ongoing Research Project

L'absence de la musique portugaise dans le contexte européen : recherche en cours d'élaboration

\section{António Pinho Vargas}

\section{OpenEdition}

\section{Journals}

Edição electrónica

URL: http://journals.openedition.org/rccs/754

DOI: $10.4000 /$ rccs. 754

ISSN: 2182-7435

\section{Editora}

Centro de Estudos Sociais da Universidade de Coimbra

Edição impressa

Data de publição: 1 Outubro 2007

Paginação: 47-69

ISSN: 0254-1106

Refêrencia eletrónica

António Pinho Vargas, «A ausência da música portuguesa no contexto europeu: Uma investigação em curso », Revista Crítica de Ciências Sociais [Online], 78 | 2007, colocado online no dia 01 outubro 2012, criado a 22 abril 2019. URL : http://journals.openedition.org/rccs/754 ; DOI : 10.4000/rccs.754

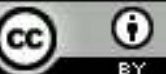




\section{ANTÓNIO PINHO VARGAS}

\section{A ausência da música portuguesa no contexto europeu: Uma investigação em curso}

Procura-se apresentar os pontos de partida teóricos de um projecto de investigação em curso com vista a uma tese de doutoramento sobre "a ausência da música portuguesa no contexto europeu". Partindo de um ponto central, a ausência da música portuguesa do cânone musical da tradição erudita europeia, trata-se de tentar analisar os processos históricos que levaram a essa inexistência e ao seu prolongamento durante todo o século XX.

\section{Introdução}

Este artigo procura apresentar os pontos de partida teóricos de um projecto de investigação em curso com vista a uma tese de doutoramento sobre "a ausência da música portuguesa no contexto europeu". Trata-se de, partindo de um ponto central, a ausência da música portuguesa do cânone musical da tradição erudita europeia, tentar analisar os processos históricos que levaram a essa inexistência e ao seu prolongamento durante todo o século XX.

Esta problemática tem vários pontos de contacto com outros debates actualmente em curso nas ciências sociais e humanas e reclama, por isso, um dispositivo teórico capaz de abarcar um âmbito de estudo alargado a partir de uma pluralidade de pontos de vista. A noção de que a realidade é sempre relacional terá de presidir à análise. Como não existe subalternidade senão em relação a uma hegemonia, a investigação tentará lançar um duplo olhar tanto sobre a ausência como sobre a hegemonia.

Neste contexto, os conceitos de "sociologia das ausências" e de "sociologia das emergências" propostos por Boaventura de Sousa Santos constituem os utensílios teóricos de base sobre os quais se poderá levar a cabo a investigação que permita depois o "trabalho da tradução", no sentido amplo do termo, isto é, enquanto prática cultural que permite a viagem, a circulação de obras de arte entre diferentes línguas e entre diferentes culturas. 
Entre as várias contribuições teóricas que permitem a análise desta problemática avultam o conceito de sistema-mundo de Braudel e Wallerstein, que enquadra a definição da sociedade portuguesa como semiperiférica, a constelação poder/saber e o conceito de discurso, proposto por Foucault, ou seja, enquanto prática que regula, organiza e reproduz a realidade que descreve (Foucault, 1972), as teorias pós-coloniais que tematizam a localização das culturas, os espaços de enunciação e "o silêncio dos subalternos" e, finalmente, os conceitos de campo e subcampo de Bourdieu, tal como aplicados pelo seu discípulo Pierre-Michel Menger em França, ao que chama "o campo da produção musical subsidiada" (Menger, 1983, 2004). No que se segue, procurarei apresentar alguns modos de aplicação destas teorias e da sociologia das ausências à temática em questão, em articulação com as contribuições provenientes da musicologia crítica que emergiu a partir de 1980 nos países de língua inglesa, nos quais é habitualmente designada como New Musicology. ${ }^{1}$

\section{Teoria}

Entre os aspectos que mais caracterizam o tempo presente pode destacar-se, primeiro, a globalização neoliberal, dominada pelos países centrais do sistema-mundo e, de acordo com a perspectiva de Immanuel Wallerstein e outros historiadores e sociólogos, o carácter de transição paradigmática que atravessamos. Para Boaventura de Sousa Santos (2001a), na actual fase, a hierarquia centro/periferia tem de ser completada pela análise da hierarquia global/local.

Será em relação a este quadro de fundo que o presente trabalho se colocará. O seu objecto - uma análise da persistente situação subalterna da música portuguesa da tradição erudita no contexto europeu - obriga ao uso de perspectivas teóricas que não se conformem apenas com a visão corrente do atraso português, do seu precário desenvolvimento cultural ou com aquilo que Eduardo Lourenço qualificou de "interiorização" da inferioridade. As teorias que melhor problematizam este tipo de questões nos últimos anos têm sido as teorias pós-coloniais. O quadro conceptual e analítico que procuro traçar parte destas contribuições que sublinham de diversas formas a localização das culturas e a importância dos lugares de enunciação.

As teorias pós-coloniais emergiram no contexto do chamado "cultural turn" dos anos 1980, a partir do trabalho de autores como Edward Said (1978) e Stuart Hall (1989) e, posteriormente, Homi Bhabha e Gayatry

\footnotetext{
${ }^{1}$ Sobre esta corrente ver Kerman, 1985; McClary, 1991; Subotnik, 1991; Cook e Everist; 1999; Williams, 2001; Kramer, 2002.
} 
Spivak. Para Bhabha, as perspectivas coloniais "intervêm nos discursos ideológicos da modernidade que tentam atribuir uma "normalidade" hegemónica ao desenvolvimento desigual e às histórias diferenciais e muitas vezes desvantajosas de nações, comunidades e povos (Bhabha, 2004: 245). Noutro ponto escreve:

Existe uma crescente convicção de que a experiência afectiva da marginalidade social - tal como emerge nas formas culturais não canónicas - transforma as nossas estratégias criticas. Obriga-nos a confrontar-nos com o conceito de cultura fora do objet d'art, ou para além da canonização da ideia de estética, a tratar a cultura como uma produção desigual, incompleta, de significado e valor. (Bhabha, 2004:246-247)²

Estes são alguns dos aspectos que justificam a utilização da teoria pós-colonial. Se se trata de impedir a aceitação da "normalidade" da subalternidade, a ausência da música portuguesa no contexto europeu só pode ser plenamente problematizada se formos capazes de ir "para além da canonização da ideia de estética".

Spivak afirma que, dado que a condição do subalterno é o silêncio, a fala é a subversão da subalternidade mas, segundo Santos, sublinha que "tornar possível esta fala exige, porém, um trabalho político que vai para além da discursividade académica". Um dos debates mais importantes nas teorias pós-coloniais trava-se em torno da questão da diversidade cultural e do multiculturalismo. Segundo Santos, enquanto, para Bhabha, "o multiculturalismo pressupõe a ideia de uma cultura central que estabelece as normas em relação à quais devem posicionar-se as culturas menores", Spivak reconhece a ampliação do cânone através do cânone multicultural, mas chama a atenção para o facto de "os textos do Terceiro Mundo serem ensinados com o total desconhecimento dos contextos históricos e políticos em que foram produzidos" (Santos, 2001b: 33).

Quer o cânone musical tradicional, quer o cânone do subcampo musical contemporâneo, que tentarei descrever mais adiante, assumem a posição hegemónica de cultura central, em relação à qual as músicas de outras culturas têm de posicionar-se. Isto é válido certamente em relação às músicas provenientes de culturas extra-europeias, mas igualmente - e este será um dos pontos principais - em relação às músicas provenientes das periferias europeias. A observação de Spivak realça a importância dos "contextos históricos e políticos em que [os textos] foram produzidos”. Diferentemente da literatura do terceiro mundo, alvo de interesse e estudo no primeiro

2 Todas as traduções são minhas. 
mundo, a música portuguesa da tradição erudita, de uma forma geral, não é conhecida nem ensinada. Em todo o caso, será esse o seu caso quando viaja: as obras musicais portuguesas não transportam consigo, de forma evidente, o traço do seu contexto.

\section{As culturas nacionais e a cultura de fronteira}

Que contexto cultural é esse? Segundo Boaventura de Sousa Santos, "nenhuma cultura é indiscriminadamente aberta; tem aberturas específicas, prolongamentos, interpenetrações e interviagens próprias", é "uma autocriação, uma negociação de sentidos que ocorre no sistema mundial". Santos tem insistido na interpretação da cultura portuguesa, no seu todo, como uma cultura de fronteira, uma cultura que "teve sempre uma grande dificuldade em se diferenciar de outras culturas nacionais [...] e manteve até hoje uma forte heterogeneidade interna". Assim, escreve, "enquanto identidade nacional, Portugal nem foi nunca suficientemente diferente das identificações positivas, as culturas europeias, nem foi nunca suficientemente diferente das identificações negativas que eram desde o século XV, os outros, os não europeus" (Santos, 1994: 133). A particularidade e a ambiguidade da cultura portuguesa no seu todo manifestam-se no campo musical do mesmo modo. A música portuguesa da tradição erudita nunca foi suficientemente diferente da europeia para se constituir como um seu "outro", nem esteve suficientemente próxima para ser vista como uma sua parte integrante.

Esta perspectiva geral sobre a cultura portuguesa e a cultura dos portugueses evita a tentação, sempre presente na forma como os portugueses fazem a sua auto-análise, de recorrer às análises essencialistas sobre uma inferioridade "natural" da música portuguesa e fornece uma nova pista de interpretação sobre a incapacidade de criar uma tradição musical ou, inversamente, sobre "capacidade de usar e transformar de forma 'barroca' tudo o que a atravessa" (Santos, 1994: 135).

\section{A problemática da ausência}

Em que consiste essa problemática? A melhor maneira de a descrever, sem a preocupação de ser exaustivo, será talvez através de algumas declarações de compositores e musicólogos portugueses em períodos diversos, sucessivamente, 1943, 1960, 2001 e 2006.

Numa conferência proferida em 1943 no Conservatório do Porto, Fernando Lopes-Graça afirmava:

O processus histórico na música portuguesa é descontínuo, cheio de hiatos, sem núcleos vitais nem figuras realmente representativas. (Graça, 1989: 15) 


\section{Mais adiante escreve:}

Onde estão porém as obras que poderiam conceder foros de existência independente, autónoma e individualizada à música portuguesa? Quais são as obras que constituem o corpus histórico da música portuguesa? (ibid.: 16)

Após referir a longa predominância em Portugal da prática da ópera italiana, que considera inautêntica, nos séculos XVIII e XIX, interroga-se Lopes Graça:

Mas possuiremos nós, em contrapartida, o génio da música sinfónica ou da música de câmara? (Graça, 1989: 21)

\section{Em 1960, escreve Lopes Graça:}

Certo e sabido: quando não se acham lamentavelmente inçadas de erros e confusões, são singularmente omissas ou parcíssimas no que respeita a Portugal as histórias da música saídas dos prelos estrangeiros.

Mas, mais adiante, interroga-se:

Os estrangeiros desprezam ou desconhecem a música portuguesa. Prezam-na ou conhecem-na todavia mais os mesmos portugueses? Que temos feito nós para a dar a conhecer, para a proteger, para a valorizar aos nossos próprios olhos e aos dos estranhos? (Graça, 1973: 100)

Para Lopes Graça há, pois, dois problemas: o primeiro é o facto de a música não ter atingido entre nós "o estádio relativamente superior dessas outras manifestações [artísticas e literárias] da nossa vida espiritual” e o segundo prende-se com a ignorância a que ela é votada quer no estrangeiro quer no próprio país.

Com outra perspectiva Alexandre Delgado escreve:

As sinfonias de João Domingos Bomtempo, Viana da Mota, Luís de Freitas Branco, Joly Braga Santos e Fernando Lopes Graça constituem um corpus de grande qualidade, que noutro país faria regularmente parte dos programas de concertos, seria estudado por especialistas e apreciado pelos melómanos. Em Portugal raramente se ouve, ninguém o estuda, poucos o conhecem. A maior parte das partituras não está editada ou é de difícil acesso; não há uma visão histórica do conjunto; algumas dessas obras não são tocadas em Lisboa há mais de 25 anos (é o caso chocante das quatro sinfonias de Luís de Freitas Branco). (Delgado, 2001: 9) 
Delgado confirma o desinteresse interno relativo à música portuguesa, apesar de considerar que existem obras portuguesas de grande qualidade. Pode concluir-se que a "ausência" começa por se manifestar dentro do próprio país através de uma atitude descuidada e negligente para com os seus artistas.

Em relação ao segundo aspecto, o desconhecimento por parte dos estrangeiros, em contraste com as afirmações anteriores, embora admitindo implicitamente o mesmo estado de coisas, Carlos de Pontes Leça escrevia em 1972 no artigo "História dum festival: o Festival Gulbenkian de 1957 a 1970":

É igualmente importante sublinhar que, ao atrair deste modo a atenção do meio internacional para o nosso país, o Festival contribuiu para que, nesse mesmo meio, despertasse um novo interesse em relação à música e aos músicos portugueses [...] O festival constituiu directa ou indirectamente um processo extremamente válido de promoção além-fronteiras da nossa música e dos nossos músicos. Aliás a eficácia dessa promoção não deve medir-se apenas pelos resultados obtidos até agora, dado que algumas portas que actualmente nos começam a dar acesso ao resto da Europa foram precisamente abertas, ou pelo menos, entreabertas, graças, em boa parte, ao Festival. (Leça, 1972: 11-12)

Mas, num texto muito recente de Paula de Azevedo Guimarães, da Direcção do Miso Music Portugal e do Centro de Informação da Música Portuguesa, criado em 2005, lê-se:

A Música Contemporânea Portuguesa e os compositores portugueses são praticamente desconhecidos fora de Portugal. Esta condição prolonga-se desde há décadas no nosso país e ameaça perpetuar-se, uma vez que não têm sido desenvolvidas as estratégias necessárias à internacionalização da música Portuguesa por parte dos sucessivos governos. ${ }^{3}$

Estes exemplos mostram diversos aspectos da "ausência" e diferentes formas de a descrever e problematizar. Corporizam os tópicos discursivos principais que reaparecem sempre que está em causa a discussão da música portuguesa de tradição erudita. Deve realçar-se não apenas a absoluta contradição entre as duas últimas convicções, mas igualmente o facto de estes discursos poderem co-existir ao longo das últimas décadas e até hoje. O que é que permite dizer que determinado festival em 1972 contribuiu

\footnotetext{
${ }^{3}$ Este texto faz parte do texto de apresentação do projecto daquelas instituições, Circuits, criado para, segundo a autora, "tentar inverter esta situação, apesar dos escassos recursos financeiros de que dispõe para o efeito" (http://www.misomusic.com/port/internacio/circuitos_main.htm).
} 
para a promoção da música portuguesa no estrangeiro e em 2006, pelo contrário, afirmar que o desconhecimento da música portuguesa no estrangeiro é uma condição que se prolonga desde há décadas no nosso país e ameaça perpetuar-se? Estar-se-á perante uma primeira fractura entre discursos institucionais e discursos dos artistas? Será que essa fractura poderá revelar-se mais complexa quando discursos de artistas evidenciam uma interiorização dos valores que comandam a instituição-arte?

$\mathrm{Na}$ verdade existe uma divisão entre a visão dos artistas e a visão das instituições. Mas mais importante ainda será tanto encontrar nos discursos institucionais o reflexo da hegemonia do centro, como igualmente descortinar, mesmo nos discursos que contestam essa hegemonia, a reprodução dos mesmos valores canónicos.

\section{Das vantagens da teoria pós-colonial}

Porque é que talvez só a teoria pós-colonial permita retirar os discursos lamentosos sobre música dos termos em que é habitualmente referida e analisada a situação subalterna da música portuguesa?

Em primeiro lugar, a teoria pós-colonial propõe uma perspectiva relacional na qual os opostos - os hegemónicos e os subalternos - são nomeados enquanto produtores de discursos que, no sentido foucaultiano, geram e reproduzem a própria realidade social que nomeiam. Assim, as razões do nosso lamento secular deixam de ser explicadas exclusivamente por todos os atrasos e insuficiências do "ser português" - uma forma discursiva recorrente que re-alimenta a subalternidade - mas passam a ser vistas e problematizadas na perspectiva do funcionamento transnacional de um campo artístico particular. Esse campo hegemónico, do qual os portugueses estão ausentes, tem, mantém e exerce um poder real e simbólico, configura uma constelação de poder/saber e tem um lugar de enunciação muito próximo do que Eduardo Lourenço designa de espaço "mais europeu” do que o resto da Europa, em tudo muito próximo das zonas de maior poder económico e político da Europa (Lourenço, 1994).

Em segundo lugar, a teoria pós-colonial, ao sublinhar a importância do espaço de enunciação, da localização da cultura, da diferença da "escrita", dos processos de "imitação" que marcam as trocas culturais desiguais - aspectos relativamente aos quais as contribuições de Homi Bhabha são fundamentais - ou ainda a consideração da "fatality of minor languages" referida por Steiner a propósito da tradução literária e da sua problemática (Steiner, 1996, 1998), fornece utensílios teóricos indispensáveis para a análise destes processos que operam, julgo, em todas as áreas de actividade: nas artes, na actividade intelectual e científica, na literatura, etc. 
Um traço disso mesmo encontra-se nas críticas dirigidas por Santos, Dussel, Mignolo e Quijano, entre outros, à concentração de grande parte dos estudos pós-coloniais nos próprios espaços dos colonialismos britânicos e francês. De certo modo, essa é uma forma de a supremacia da modernidade do Norte da Europa conseguir infiltrar-se e reproduzir-se no próprio campo de estudos que a contesta. Estes autores salientam a necessidade de se ter em conta as diferenças fundamentais entre aqueles colonialismos e os colonialismos ibéricos.

Dussel refere que, por altura do Congresso de Berlim, "o Sul da Europa ficaria, na memória eurocêntrica do Norte (anglo-saxónico e alemão), como um momento da "Idade Média" tardia ou como "a parte norte de África". No mesmo sentido, assinala que "a exclusão, como critério civilizacional, de tudo o que não fosse europeu, permitiu também à Europa - que já tinha a hegemonia militar, económica e política - a dominação cultural e ideológica”. Mais adiante acrescenta ainda: "A Espanha e Portugal (no que respeita à primeira modernidade), os Chineses, os Hindustanos e os membros do mundo Islâmico [...] acabariam por aceitar a interpretação eurocêntrica dos países do Norte" (Dussel, 2002: 232).

É importante sublinhar esta posição de Dussel quando afirma que Portugal e a Espanha acabaram por aceitar como válida a interpretação eurocêntrica dos países do Norte, a mesma interpretação que os excluiu da modernidade. Dussel distingue entre a primeira modernidade dominada pelos países ibéricos no séculos XV e XVI e a segunda modernidade, a modernidade do Iluminismo, aquela que nós hoje tomamos por adquirida como sendo a Modernidade. De acordo com a teoria proposta por Dussel, o campo dos excluídos da hegemonia global europeia alarga-se aos países ibéricos. Nessa perspectiva, ganham uma outra relevância as análises de Eduardo Lourenço sobre as relações entre Portugal e a Europa e as análises de Boaventura de Sousa Santos sobre os momentos de Prospero e Caliban característicos do colonialismo português. Os escritos de Lourenço mostram que a relação de Portugal com a Europa foi sempre uma relação de distância e diferença mais do que propriamente de pertença. Em "Nós e a Europa: ressentimento e fascínio", pode ler-se:

O que a disjuntiva [ressentimento e fascínio] revela é a consciência de uma distância, de uma marginalidade, talvez sobretudo, de uma como que fatal dependência ou inferioridade do tipo de cultura, e dos exemplos mais elevados quando a considerávamos nessa espécie de espelho abstracto mas singularmente mágico onde brilham [...] as estrelas fixas do céu cultural europeu. (Lourenço, 1994: 25) 


\section{Boaventura de Sousa Santos refere o facto de os Portugueses}

terem sido o único povo europeu que ao mesmo tempo que observava e considerava os povos das suas colónias como primitivos e selvagens, era ele próprio, observado e considerado, por viajantes e estudiosos dos países centrais da Europa do Norte como primitivo e selvagem. (Santos, 1994: 133).

No artigo "Entre Prospero e Caliban", o autor refere que "como afirma Castelo Branco Chaves, é a partir da segunda metade do século XVIII, e por invenção sobretudo dos ingleses, que a 'lenda negra' de Portugal e dos Portugueses como povo decaído, degenerado, imbecilizado mais se aprofunda". Se pensarmos ainda na reconstrução levada a cabo por Pereira Bastos sobre "o perfil do português saído dos estudos do sociólogo francês Paul Deschamps" nos anos 30 a convite de Salazar, percebemos que "mais importante ainda é que, em pleno século XX, muitas das características atribuídas aos Portugueses têm semelhanças surpreendentes com as narrativas colonialistas, inclusive as portuguesas, atribuíam ao negro africano, ao escravo americano ou ao índio americano" (Santos, 2001b: 53).

Pode perguntar-se até que ponto é que estas representações dos Portugueses pelos europeus do Norte ainda se mantêm hoje, sob a forma de resquícios ou sedimentos de um olhar de tipo colonial. O processo que leva à supremacia da segunda modernidade ocorre, historicamente, em sincronia com a formação do cânone da "Western art music" que veremos de seguida (Goehr, 1992). Tendo isso em conta, o facto de o interesse dos europeus em geral relativamente à música portuguesa se dirigir, ainda hoje, principalmente para o fado, uma expressão artística local, vernácula, popular e urbana, em paralelo com o desinteresse e a ignorância de outras expressões "cultas", na verdade, tratadas como inexistentes, pode ser significativo da forma como Portugal é visto quando olhado da Europa. ${ }^{4}$

\section{O cânone musical europeu}

A formação do cânone da música ocidental verificou-se no mesmo período histórico que corresponde à formação da segunda modernidade e consiste num corpo de obras - as obras-primas dos grandes mestres - com presença regular nas salas de concertos e nos teatros de ópera do mundo. Para Joseph

\footnotetext{
${ }^{4}$ Para Santos, "existem ainda os que contribuem fortemente para a globalização mas, não obstante, permanecem prisioneiros do seu espaço tempo local" e, noutro ponto, "noutra perspectiva a competência global requer, por vezes, o acentuar da especificidade local" (Santos, 2001a: 70). Este será o caso do fado que consegue, por vezes, ser globalizado enquanto portador de especificidade local.
} 
Kerman, existe uma segunda função associada ao cânone: um conjunto de peças que representam um modelo para a composição. O cânone musical permaneceu estável durante algum tempo, mas deve sublinhar-se que a instabilidade é igualmente característica. Algumas obras esperaram décadas ou séculos para integrar o cânone do repertório, enquanto outras nunca atingiram o carácter exemplar de modelos para a composição (Kerman, 1985, 1994).

Sobre o poder do cânone, escreve Katherine Bergeron:

O cânone implica por isso um tipo de controlo social - um controlo que inevitavelmente se estende a um corpo social mais vasto [...] defender o cânone é, em ultima análise, interiorizar os valores que manteriam, por assim dizer, a harmonia social.

Bergeron faz-se eco de problemáticas actualmente correntes em muitas ciências sociais nomeadamente nos estudos pós-coloniais:

Os limites do campo - as fronteiras que, ao demarcarem um interior, significam a presença de uma ordem - indicam igualmente um exterior, um espaço para além do delimitado, onde os valores já não podem ser medidos. (Bergeron e Bohlman, 1996: 2)

O cânone, ao estabelecer limites e fronteiras no interior do campo musical, declara ao mesmo tempo a sua exterioridade: determina aquilo que fica do lado de fora desses limites.

Mas Bergeron vai mais longe, apoiando-se em conceitos de Foucault, na abordagem do carácter disciplinar associado ao cânone:

O cânone representa uma escala de valores. Os Grandes Homens aí inscritos são os escolhidos, retirados de uma longa história da música [...]. Os estudantes desta história, sintonizados com os seus valores, aprendem a reproduzi-los, a segmentar da mesma forma, de acordo com a disciplina. Este, poderia dizer-se, é o impacto social do cânone. (ibid:: 2)

Para a autora, "traduzidos numa prática, os seus valores [do cânone] podem ser interiorizados" (ibid.: 2). Nesta direcção, uma das hipóteses de trabalho será interrogar até que ponto a música portuguesa ou os músicos e compositores portugueses aceitam e se conformam com os valores recebidos, no processo descrito por Bergeron e, consequentemente, com a sua própria exterioridade. A ausência da música portuguesa do cânone musical europeu é um facto. Nenhuma obra, nenhum compositor o integrou alguma 
vez. Mas será muito discutível concluir daí que a música portuguesa da tradição erudita seja um "Outro" da música europeia. Por um lado, todo o sistema de ensino é baseado na transmissão dos valores e nos exemplos do cânone musical; por outro, a programação musical das instituições culturais é organizada e regulada pelos mesmos valores. Até os compositores, produtores de obras que sempre ficaram no exterior do cânone, por isso mesmo os mais claramente excluídos, não deixam de encarar a sua actividade com um sentimento de pertença à tradição musical europeia que reveste muitas vezes a forma de uma "imaginação do centro" (Santos, 1993: 49-53). Verifica-se um desajuste entre a ligação à tradição ocidental, essa pertença imaginada, e a realidade, unicamente capaz de produzir objectos artísticos subalternos não reconhecidos como capazes de integrar de pleno direito a tradição da qual aspiram fazer parte.

Assim sendo, a aplicação dos conceitos de "conhecimentos subalternos", proposta por Foucault (1976), e de "línguas menores” de que falam George Steiner e Gilles Deleuze, poderá permitir uma abordagem teórica da problemática em causa de um modo menos discutível. Ou, ainda noutra perspectiva, talvez seja mais plausível inverter os termos da formulação inicial e perguntar se, do ponto de vista dos Portugueses, a música europeia não terá sido, ou não será ainda, um Outro que se pretende, e sempre se pretendeu, emular?

\section{Sobre a questão da hegemonia cultural}

A hegemonia cultural dos países centrais do sistema-mundo, que concentram a produção e difusão dos bens culturais, dos artistas "internacionais", é recebida e interpretada como natural, como doxa - o não-interrogado -, e reproduz nos agentes culturais locais os seus próprios valores transformando-os em difusores locais dos valores hegemónicos.

O carácter dos bens culturais recebidos do centro, o seu prestígio simbólico, alicerçado e reproduzido em numerosas publicações - revistas, jornais, edições discográficas, livros de referência no ensino - tem sido, de algum modo, inexpugnável à crítica. Tem como base um conjunto de valores canónicos que se expressam e disseminam através de discursos estéticos emanando igualmente do centro, facilmente recebidos como "universais", ou seja, como imediatamente válidos em qualquer lugar. Estes discursos que, ao mesmo tempo, revestem, criam e fazem parte da supremacia real, incluem juízos de valor estético sobre obras e tendências. Quando são recebidos nos países periféricos, chegam rodeados de uma aura indestrutível muito difícil de desmontar.

A armadilha que estes discursos transportam reside na tentação de discutir, não a hegemonia enquanto tal, mas os juízos de valor estéticos. 
Este trabalho procura evitar essa armadilha e, por isso, não lhe cabe fazer qualquer análise musical de qualquer obra portuguesa, nem emitir qualquer juízo de valor. Esse exercício de legitimação pela via analítica estaria, de qualquer modo, condenado à ineficácia - enquanto legitimação uma vez que a própria disciplina de análise musical tem sido objecto de debates violentos entre os adeptos da análise formalista e os adeptos da análise contextual e já não possui a capacidade de declarar "científicas” as suas conclusões. É relativamente óbvio que os defensores da análise formalista são igualmente adeptos da visão canónica da música e do valor exclusivo da obra-em-si, posição que Richard Taruskin qualifica de ideologia da "music-itself" (Taruskin, 2000, 2005). A análise musical, os seus métodos e os seus debates internos fazem parte integrante da hegemonia e o seu uso legitimador nunca foi inocente, nem a sua aplicação "científica".

Por outro lado, se os motivos da "morte da música clássica" e da crise permanente da "nova música", presentes em textos académicos quer na Europa, quer nos Estados Unidos - e totalmente ausentes em Portugal o que, só por si, será uma marca de exterioridade -, merecem uma abordagem na medida em que manifestam a fractura do cânone e a questão da actual irrelevância social da música contemporânea, uma segunda armadilha poderá derivar das análises dos públicos dos grandes eventos culturais em que se têm concentrado os estudos sociológicos realizados em Portugal. A análise destes aspectos, apesar do seu inegável interesse, poderá, de algum modo, ocultar os processos de dominação transnacional que constituem o objecto principal desta investigação. A sociologia dos públicos e dos gostos - levada a cabo exemplarmente por Bourdieu e, no nosso país, por outros autores - trata principalmente o consumo cultural mas não investiga os processos hegemónicos da oferta no âmbito transnacional ou global.

\section{A constituição do subcampo}

Nesta medida, é necessário proceder à análise dos desafios que, a partir do início do século XX, o modernismo colocou ao cânone tradicional e o considerável impacto - de várias formas - da reprodutibilidade técnica no campo musical actual.

Nos países centrais da Europa, dispondo há muito tempo das estruturas materiais e institucionais que regulam o funcionamento da vida musical ocidental, prevalece em larga escala, a ideologia do cânone ocidental. Mas pode acrescentar-se, seguindo Pierre-Michel Menger, que se terá constituído, sobretudo após 1945, um subcampo contemporâneo, dotado de novas 
estruturas de funcionamento: ensembles, solistas, festivais, programadores e críticos especializados, etc.:

Tem os seus actores, os seus auditores, mas também o pessoal das administrações culturais e das cadeias de radiodifusão públicas que financiam e sustentam a produção e a difusão de obras que não têm mercado directo ou imediato. Tem os seus mecenas, menos activos onde, como na Europa, a política cultural do Estado contribuiu para a formação de mercados administrados da inovação, mais requisitados no mundo anglo-saxónico onde a intervenção pública não beneficia de uma tradição nem de uma legitimidade indiscutível. Tem a sua cronologia institucional - a da invenção dos ensembles especializados, dos festivais, dos centros de pesquisa e de produção - e os seus apoios fora das instituições (salões privados, associações, lugares alternativos de difusão). (Menger, 2003: 1169)

Estas novas estruturas de funcionamento e o seu pessoal especializado surgiram como consequência do cisma estético modernista que se aprofundou fortemente após 1945 no campo musical. No entanto, apesar de criado em ruptura com o campo musical "clássico", este subcampo contemporâneo, para além de partilhar a mesma localização central, ou seja, o mesmo espaço de enunciação, reproduziu, sob diversas formas, as hegemonias herdadas do período histórico anterior. Embora fracturado parcialmente em relação aos valores tradicionais da música tonal e desintegrado em múltiplas correntes após a crise e a crítica pós-moderna, reconstituiu e reproduz os mesmos processos hegemónicos em relação às periferias da Europa e do resto do mundo.

Este processo foi complexo e torna-se difícil de desmontar na medida em que, tal como os valores do cânone dominam as práticas musicais tradicionais, os valores do que pode chamar-se o subcampo contemporâneo são, como já foi dito, igualmente hegemónicos, quer nas programações culturais, quer no ensino da composição, quer ainda nos próprios agentes artísticos - os compositores - que muitas vezes actuam motivados pela emulação do centro.

O procedimento que Santos designa por "sociologia das ausências" pode ter aqui um campo de aplicação exemplar. Para Santos, "trata-se de uma investigação que visa demonstrar que o que não existe é, na verdade, activamente produzido como não existente [...] como alternativa não-credível ao que existe." (Santos, 2006: 95).

Se o objecto principal é a ausência da música portuguesa do contexto europeu, o objecto complementar correspondente será a identificação do lugar de enunciação especifico, localizado num determinado espaço geo- 
político, no qual se decretam as inclusões e as exclusões, no qual existe o poder de declarar e institucionalizar o local próximo como global e o local afastado como local.

\section{O lugar de enunciação}

Um dos factores em jogo é, justamente, a verificação do lugar de enunciação da chamada nova música, o lugar que tem a capacidade de determinar o que é contemporâneo e de declarar o que é local ou global.

No campo da indústria cultural de massas globalizada, está razoavelmente estabelecido que o centro de irradiação dos produtos - filmes, séries de televisão, música, jogos de computador, etc. - está nos Estados Unidos e na Grã-Bretanha; é crucial que as análises dessa indústria tenham em conta a forma como o crítico norte-americano Fredric Jameson se refere a um dos aspectos principais da globalização: "um dos caminhos óbvios é aquele em que globalização significa importação/exportação de cultura. Esta é, sem dúvida, uma questão de negócios" (Jameson, 1998: 58). Os discursos excessivamente culturalistas podem por vezes ocultar e fazer esquecer o funcionamento da economia no campo cultural.

De outro modo, não é enquanto "business" que as relações de poder se revelam no subcampo contemporâneo, embora possa dizer-se que as relações "import/export" culturais não devem ser negligenciadas mesmo nesta esfera.

Uma das hipóteses mais bem estabelecidas neste momento prende-se com a identificação do lugar de enunciação da música contemporânea depois de 1945 até hoje. A partir dessa altura, tornou-se gradualmente mais notória nos países do centro europeu a emergência de uma figura nova: o compositor emigrante, proveniente dos diversos pontos do globo nos quais a cultura ocidental adquiriu uma posição de dominação em relação às culturas tradicionais.

Limitando-me aos casos mais relevantes posso referir o caso de Maurício Kagel, argentino que emigrou em 1957 para a Alemanha, onde hoje vive, de Iannis Xenakis, grego que emigrou em 1947 para França, onde faleceu, de György Ligeti, que saiu em 1956 da Hungria para a Alemanha, onde faleceu em 2006, de Isang Yun, vindo em 1955 da Coreia para a Alemanha, onde faleceu em 1995, do húngaro Peter Eotvos, na Alemanha desde 1966, do romeno Horaciu Radulescu, em França desde 1969, do búlgaro André Boucourechliev, em França desde 1949, e de muitos outros.

Todos estes compositores se radicaram definitivamente nos países centrais nos quais, na verdade, existiam as estruturas associadas à nova música: as editoras com as quais assinaram contratos, as rádios que davam apoios e 
divulgação, as instituições culturais capazes de encomendar obras, as orquestras, os festivais, as publicações, etc. Este processo da emigração de compositores de zonas periféricas para os países centrais explica-se, sem dúvida, pela concentração de recursos nesses países, pelo carácter muito especializado das correntes musicais dominantes nesse período, pelo contexto político-cultural da guerra fria que favoreceu, no Ocidente, o apoio em larga escala aos artistas de vanguarda contra a arte soviética de carácter "realista" e antiformalista, mas também pelo facto de, permanecendo nas periferias, se ficar condenado à fatalidade das "línguas menores", ou seja, a uma determinada forma de inexistência. Há dois outros aspectos que importa referir. Em primeiro lugar, a evolução política pós-1989 agudizou ainda mais este processo com a emigração de compositores oriundos da ex-União Soviética e dos seus satélites (como Sofia Gubaidulina (1992), Alfred Schnitke (1990), Arvo Part (1980), Giya Kancheli (1992) Victor Suslin (1981), György Kurtag (1993), todos para a Alemanha, Elena Firsova (1991), Dmitri Smirnov (1991), para a Inglaterra. Em segundo lugar, a centralidade adquirida pelo IRCAM, instituição fundada e dirigida por Pierre Boulez em 1978, considerada por Jean-Jacques Nattiez "a mais gigantesca operação de salvamento de uma arte contemporânea que alguma vez um Estado pôs à disposição de um compositor" (Nattiez, 1984: 353-354) promoveu uma deslocação regular e, por vezes, definitiva, de compositores provenientes de outros países para Paris, como os finlandeses Magnus Lindberg e Kaija Saariaho (1982 em Paris), a coreana Unsuk Chin (na Alemanha desde 1985), o português Emmanuel Nunes (desde 1964), o argentino Martin Matalon, o italiano Marco Stroppa e muitos outros. Mesmo nos casos de compositores de países que, de outro modo, se poderiam considerar centrais, como a Inglaterra, é de notar que tiveram importantes e repetidas passagens pelo IRCAM os compositores Jonathan Harvey, Brian Ferneyhough, Harrison Birswitle, George Benjamin e o americano Tod Machover. Estes casos sublinham o facto de a passagem pelo IRCAM se ter tornado quase obrigatória para legitimar uma posição de distinção no interior do subcampo contemporâneo.

À emigração para o centro correspondeu, do ponto de vista musical, a adopção dos princípios fundamentais das correntes dominantes com destaque para o pós-serialismo, ainda hoje uma tendência muito importante no campo. A teoria pós-colonial de Bhabha designa este processo de "mimicry"; o fascínio exercido pela metrópole sobre o emigrante manifesta-se no desejo de ser igual e, neste campo musical, quase nunca se vislumbra um traço de "otherness". Este processo, que se verifica com artistas e intelectuais tem a seu oposto literal nos processos maciços de emigração das ex-colónias para as metrópoles ex-coloniais do Ocidente. Ao contrário do emigrante 
individual e culto, motivado pela atracção estética e vivencial exercida pelo espaço de enunciação do centro musical, as largas camadas de população provenientes das ex-colónias das potências europeias levam consigo a sua língua e a sua cultura, que, sendo quase sempre de tradição oral, permite entabular processos de miscigenação e hibridismo com o pop-rock anglo-americano, dotado de uma esmagadora hegemonia global. Pelo contrário, a questão multicultural tem pouquíssima expressão no subcampo contemporâneo. A preocupação do "travelling composer" não é afirmar a sua diferença, mas maximizar as suas possibilidades de integração no campo, absorver as suas técnicas, cultivar as suas maneiras e integrar-se no modo de expressão pré-existente. Apesar das grandes mutações politicas ocorridas entre 1945 e 2000, o destino da viagem do "travelling composer" continuou circunscrito quase exclusivamente a dois dos países centrais, a França e a Alemanha.

Com base em análises empíricas destes dados é possível descrever o subcampo da música contemporânea também como um determinado espaço de enunciação fora do qual qualquer expressão artística parece condenada ao seu carácter local e, por conseguinte, ao silêncio e à ausência do espaço transnacional.

A importância da identificação deste espaço de enunciação específico da música contemporânea e do seu subcampo verifica-se ainda noutros aspectos. A inclusão de uma obra de um "travelling composer" num festival europeu, entre 1950 e 2000, nunca significou uma atenção a uma música proveniente de um seu "exterior", mas simplesmente a inclusão de um agente activo, próximo e integrado no campo, deslocalizado em relação à sua origem e relocalizado no centro. Mais concretamente, do ponto de vista das instituições e dos programadores especializados do centro, a apresentação de uma obra de Xenakis, de Kagel, de Ysang Yun ou de Nunes, não implicava que houvesse por parte dos organizadores interesse programático em relação à música grega, argentina, coreana ou portuguesa. Significava, sim, que o campo, ao constituir-se como universal, ao considerar as obras como obras-em-si e compositores como autores individuais, sem ligações a nenhum contexto particular - por isso, universais -, o núcleo duro do subcampo incluía obras desses autores enquanto autores que lhe eram próximos, que habitavam e partilhavam o mesmo espaço de enunciação, que a ideologia prevalecente impede de considerar senão como "universal".

É em relação a este espaço assim constituído, aos seus critérios de funcionamento e à sua capacidade de irradiação, que deve analisar-se a ausência da música portuguesa e não apenas em relação ao "estrangeiro", a designação genericamente referida nos exemplos acima citados. 
Como se processa a exclusão das produções locais, nacionais, externas, como se processa a recepção do trabalho artístico extraterritorial?

\section{A produção activa de não-existência}

Boaventura de Sousa Santos identifica cinco lógicas ou modos de produção de não-existência. Irei passar em revista essas lógicas tendo em vista a sua aplicação a esta esfera da actividade cultural.

Para Santos,

[h]á produção de não-existência sempre que uma entidade é desqualificada e tornada invisível, ininteligível ou descartável de um modo irreversível. O que une as diferentes lógicas de produção de não-existência é serem todas elas manifestações da mesma monocultura racional. (Santos, 2006: 95)

Boaventura de Sousa Santos distingue cinco lógicas ou modos de produção de não-existência. A primeira lógica é designada por monocultura do saber e do rigor do saber. Considerando-o o modo de produção de não-existência mais poderoso, Santos escreve que "consiste na transformação da ciência moderna e da alta cultura em critérios únicos de verdade e de qualidade estética, respectivamente". Ambas se arrogam ser "cânones exclusivos de produção de conhecimento ou de criação artística. Tudo o que o cânone não legitima ou reconhece é declarado inexistente. A não-existência assume aqui a forma de ignorância ou de incultura" (Santos, 2006: 95-96).

Um dos aspectos referidos por Lopes Graça no passo acima citado, refere-se à inexistência da música portuguesa no próprio interior do país. Julgo que a investigação realizada até este momento permite antecipar a conclusão de que, durante o século XX, as instituições culturais portuguesas tiveram um papel activo na produção de não-existência. $\mathrm{O}$ meu objecto de análise ocupa um lugar ambíguo. Internamente, faz parte da "alta cultura" onde ocupa um lugar subalterno, de elevada irrelevância social, mas externamente é descartado porque o seu espaço de enunciação está longe dos centros. A sua não-existência assume a forma de expressão local e de subalternidade interna e externa. As instituições culturais nacionais - que, não obstante, encomendam e apresentam obras, de acordo com as declarações de princípios que ostentam - regulam-se por critérios de programação que promovem activamente a hegemonia do centro e, ao mesmo tempo, descartam muitas vezes as próprias obras que encomendam após as estreias (as obras raramente são repetidas pelas instituições que as encomendam). Cumprindo essa função simbólica - apoiar a produção 
local - mas tendo integrado como universais, e por isso também como seus, os valores centrais que disseminam localmente, as instituições culturais repetem anualmente grandes mostras de artistas "internacionais" de acordo com redes de agentes que fidelizaram, com viagens prospectivas regulares ao centro para comprar espectáculos e manifestam total incapacidade de negociar uma exportação cultural com o centro numa base de igualdade, de uma política de troca e contacto cultural transnacional. A sua função local principal é importar e está naturalizada como tal. A crítica especializada, apesar de algumas referências dispersas à inexistência, tem como tarefa principal, igualmente naturalizada, dar conta dos eventos justamente mais importantes do ponto de vista hegemónico que ocorrem nas principais instituições culturais.

A segunda lógica, a monocultura do tempo linear, para Santos "assenta na monocultura do tempo linear, a ideia de que a história tem sentido e direcção únicos e conhecidos. Esse sentido e essa direcção têm sido formulados de diversas formas nos últimos duzentos anos: progresso, revolução, modernização, desenvolvimento, crescimento, globalização. Comum a todas estas formulações é a ideia de que o tempo é linear e que na frente do tempo seguem os países centrais do sistema mundial e, com eles, os conhecimentos, as instituições e as formas de sociabilidade que neles dominam" (Santos, 2006: 96).

Esta lógica fornece às instituições culturais portuguesas o princípio base no qual assentam os critérios que de certo modo neutralizam aquilo que elas próprias produzem. Se "na frente do tempo seguem os países centrais do sistema mundial" então é neles que se assegura e se contratualiza - se compra, se divulga, se critica - aquilo que, mesmo antes de chegar, já contém em si a propriedade de ir à frente, de "estar mais avançado no tempo".

Para Sousa Santos, é de acordo com esta lógica que "a modernidade ocidental produz a não-contemporaneidade do contemporâneo, a ideia de que a simultaneidade esconde as assimetrias dos tempos históricos que nela convergem" (ibid.: 96). Esta concepção de temporalidade é tão operativa no campo económico como no campo das artes. Nesse sentido, é o fundamento da visão teleológica que persiste igualmente nas visões da maior parte das histórias da música, nas narrativas da evolução da linguagem musical e nos discursos pedagógicos do ensino musical. Aqui radicam igualmente as formas discursivas dominantes na crítica e nos critérios de selecção das instituições. A frase de Lopes Graça no artigo de 1943, "De então para cá [fins do séc. XVII] nunca mais a música portuguesa acertou o seu passo pelo da evolução geral da música europeia” (Graça, 1973: 17), corresponde à formulação habitual do atraso ou do desfasamento baseado nesta concep- 
ção do tempo. De entre tudo o que é simultâneo, nem tudo é contemporâneo. Que tal tenha sido escrito em 1943 não será de admirar, uma vez que a crítica da concepção linear da temporalidade ocidental não fora ainda formulada, mas, na verdade, continua a ser a perspectiva dominante tanto nos discursos políticos como nos discursos sobre as artes em geral e a música portuguesa em particular.

A terceira lógica é a lógica da classificação social e "assenta na monocultura da naturalização das diferenças. Consiste na distribuição das populações por categorias que naturalizam hierarquias" (Santos, 2006: 96). Para Santos, "a não existência é produzida sob a forma de inferioridade insuperável porque natural". Não assume no campo musical uma expressão diversa daquela que assume na imprensa diária sempre que alguém escreve "os Portugueses" como signo de inferioridade. Circula na sociedade de forma intensa, particularmente nas elites culturais, e manifesta-se, por exemplo, no critério interiorizado pelas instituições culturais nas negociações de cachets com os artistas nas quais é recorrente haver duplicidade de critérios desfavorável aos portugueses. Sousa Santos salienta que esta lógica, a classificação social, "assenta em atributos que negam a intencionalidade da hierarquia social" (ibid.: 96).

A quarta lógica da produção de inexistência é a lógica da escala dominante. Santos sugere que "nos termos desta lógica a escala adoptada como primordial determina a irrelevância de todas as outras possíveis escalas". Para o autor, "o universalismo é a escala das entidades ou realidades que vigoram independentemente de contextos específicos. Têm, por isso, precedência sobre todas as outras realidades que dependem de contextos e que por essa razão são consideradas particulares ou vernáculas”. Mais adiante, escreve: "No âmbito desta lógica, a não-existência é produzida sob a forma do particular e do local. As entidades ou realidades definidas como particulares ou locais estão aprisionadas em escalas que as incapacitam de serem alternativas credíveis ao que existe de modo universal ou global". Para Santos, trata-se da escala que privilegia as entidades que alargam o seu âmbito a todo o globo. "As entidades ou realidades definidas como particulares ou locais estão aprisionadas em escalas que as incapacitam de serem alternativas credíveis ao que existe de modo universal ou global" (Santos, 2006: 96-97).

Esta lógica é a que parece ser de mais directa aplicação à temática deste trabalho. Pode afirmar-se que a música portuguesa é "uma realidade que depende de contextos" e assim tem sido "aprisionada" na sua escala local e, mesmo no interior do país, não consegue "ser alternativa credível ao que existe de modo universal ou global”. O prestígio do cânone musical, a 
aceitação implícita do seu carácter universal na maior parte dos discursos e das práticas é o fundamento da quase toda a actividade musical. Por outro lado, a problemática do global e do local não deixa de ser central e omnipresente, mesmo quando não é nomeada enquanto tal. A música portuguesa é local. As "grandes orquestras mundiais" são globais. No campo musical, as expressões discursivas de uso mais corrente que estabelecem a diferenciação são, por exemplo, "uma programação de nível internacional", "os grandes artistas internacionais" ou, nos casos em que se fazem comparações ou juízos de valor, "ao nível do que de melhor se faz lá fora".

No entanto, esta problemática encerra algumas questões. O cânone musical europeu vê-se a si próprio como universal, mas será global? O seu carácter minoritário frente à avassaladora primazia da "pop culture" na indústria cultural audiovisual modifica o seu estatuto? Como se pode analisar o caso da música contemporânea, um subcampo de circulação ainda mais restrita, nesta perspectiva global/local, quando tem sido, nos próprios países centrais, objecto de inquietação?

A quinta lógica, a lógica produtivista, parece ser de aplicação mais difícil à temática em questão, na medida em que o compositor português compõe e, por isso, não pode ser acusado de improdutividade. No entanto, é na articulação complexa destas diversas lógicas que o nosso objecto de análise se configura como ausência e que o funcionamento das instituições culturais, tal como tem sido, assume o papel de produtor activo de inexistências.

\section{Paráfrases}

A partir das conclusões que Boaventura de Sousa Santos retira do seu projecto "A Reinvenção da Emancipação Social" (Santos, 2006), proponho paráfrases literais transpostas para o meu campo de análise.

Paráfrase 1: A diversidade das práticas musicais e das obras compostas é muito mais vasta do que o subcampo europeu da música contemporânea - festivais, editoras discográficas e editoras de partituras - conhece e considera importante.

Paráfrase 2: Esta produção musical tem sido desperdiçada. Deste desperdício, derivam as ideias sobre a crise da música contemporânea, vista como incapaz de se renovar a si própria. Como o que não é conhecido não pode ser avaliado, a classificação destas produções é baseada numa consciência parcial e numa ignorância parcial.

Paráfrase 3: Para lutar contra este desperdício, para tornar visíveis estas produções musicais, contar com as instituições musicais tal elas como se configuram actualmente tem pouca utilidade. Não tem sentido propor um tipo de organização das instituições culturais semelhante àquelas que já 
existem, como o IRCAM e os festivais de música contemporânea. A racionalidade ocidental que constituiu o cânone musical também produziu os tipos de dominação hegemónica existentes no subcampo musical contemporâneo. Esses tipos de dominação estão muito próximos do modo de funcionar das instituições tradicionais do cânone musical europeu e da sua capacidade de se reproduzir durante pelo menos duzentos anos. Todas as propostas apresentadas, por mais que se considerem alternativas tenderão a reproduzir o mesmo efeito de silenciamento, de ocultação, de arrogância e descrédito.

A principal tarefa hoje, para Sousa Santos, é a necessidade de um modelo diferente de racionalidade. Nesse sentido, uma tentativa de construir um mapa alternativo, um outro mapa cognitivo usando a imaginação cartográfica, como o autor propõe, é a maior dificuldade deste trabalho de investigação. Estamos muito próximos do Noch Nicht, do ainda-não de Ernst Bloch, de qualquer coisa que tanto pode emergir como não emergir. A interiorização da subalternidade, activa em todos os agentes de diversas formas, poderá ser dissolvida numa nova capacidade criativa ou ser submetida e subsumida pelos critérios hegemónicos do centro. Há alguns factores na presente vida musical portuguesa que podem criar algumas expectativas, mas são ainda muito inseguros, muito frágeis e, pelo contrário, o poder dos valores simbólicos do centro continua sempre muito forte.

Nesse sentido, prosseguir esta investigação implica considerar essa dupla possibilidade no período posterior a 2000: a hipótese de uma reconfiguração ideológica interna que modifique as práticas que têm produzido a inexistência, ou a hipótese de, sob o véu aparente de cosmopolitismo que tem presidido à orientação geral, se continuar a ignorar a real subalternidade transnacional que afecta uma comunidade artística.

\section{Referências bibliográficas}

Bergeron, K.; Bohlman, P. V. (1996), Disciplining Music: Musicology and Its Canons. Chicago: The University of Chicago Press.

Bhabha, H. K. (1990), "The Third Space. Interview with Homi Bhabha", in Jonathan Rutherford (org.), Identity. Community, Culture, Difference. London: Lawrence and Wishart, 207-221.

Bhabha, H. K. (2004), The Location of Culture. London: Routledge. Cook, N.; Everist, M. (1999), Rethinking Music. Oxford: Oxford UP. Delgado, Alexandre (2001), A sinfonia em Portugal. Lisboa: IPAE/RDP.

Dussel, Enrique (2002), "World-System and 'Trans'-Modernity”, Neplanta: Views from the South, 3(2), 221-244. 
Foucault, Michel (1972), The Archaeology of Knowledge. London: Tavistock Publications, 78-108.

Foucault, Michel (1980), “Two Lectures, 1976”, in Colin Gordon (org.), Power/Knowledge: Selected Interviews and Other Writings, 1972-1977. London: Longman.

Goehr, L. (1992), The Imaginary Museum of Musical Works: An Essay in the Philosophy of Music. Oxford/New York: Clarendon Press/Oxford UP.

Graça, Fernando Lopes (1973), “Os historiadores estrangeiros e a música portuguesa”, in F. L. Graça, A música portuguesa e os seus problemas, vol 3. Lisboa: Cosmos, 13-34.

Graça, Fernando Lopes (1989), “Criação e crítica na música portuguesa”, in F. L. Graça, A música portuguesa e os seus problemas, vol 1. Lisboa: Caminho, 97-100.

Hall, Stuart (1989), "New Ethnicities”, in David Morley; Kuan Hsing Chen (orgs.), Stuart Hall: Critical Dialogues in Cultural Studies. London/New York: Routledge, 441-449.

Jameson, Fredric (1998), "Notes on Globalization as a Philosophical Issue”, in F. Jameson; M. Miyoshi (orgs.), The Cultures of Globalization. Durham/London: Duke UP, 54-80.

Kerman, J. (1985), Contemplating Music: Challenges to Musicology. Cambridge, MA: Harvard UP.

Kerman, J. (1994), Write All These Down: Essays on Music. Berkeley, CA/London: University of California Press.

Kramer, L. (2002), Musical Meaning: Towards a Critical History. Berkeley, CA: University of California Press.

Leça, Carlos Pontes (1972), "História dum festival: o Festival Gulbenkian de 1957 a 1970", Colóquio/Artes, 7, 1-12.

Lourenço, Eduardo (1994), Nós e a Europa ou As duas razões. Lisboa: INCM.

McClary, S. (1991), Feminine Endings: Music, Gender, and Sexuality. Minneapolis/Oxford: University of Minnesota Press.

Menger, P.-M. (1983), Le paradoxe du musicien: le compositeur, le mélomane et l'Etat dans la société contemporaine. Paris: Flammarion.

Menger, P.-M. (2004), “Le public de la musique contemporaine”, in J.-J. Nattiez (org.), Musiques, une encyclopédie pour le XXI Siècle. Arles: Actes Sud/Cité de la Musique, vol. 1, 1169-1186.

Nattiez, J.-J. (1984), “Tonal/Atonal”, Enciclopédia Einaudi. Lisboa: INCM, vol. 3, 331- 356.

Said, E. W. (1978), Orientalism. Harmondsworth: Penguin.

Santos, Boaventura de Sousa (1993), Portugal: Um retrato singular. Porto: Afrontamento.

Santos, Boaventura de Sousa (1994), Pela mão de Alice: O social e o político na pós-modernidade. Porto: Afrontamento.

Santos, Boaventura de Sousa (2001a), "Os processos da globalização", in B. S. Santos (org.), Globalização: Fatalidade ou utopia?. Porto: Afrontamento, 31-106. 
Santos, Boaventura de Sousa (2001b), "Entre Prospero e Caliban. Colonialismo, pós-colonialismo e inter-identidade”, in Maria Irene Ramalho; António Sousa Ribeiro (orgs.), Entre ser e estar. Raízes, percursos e discursos da identidade. Porto: Afrontamento, 23-85.

Santos, Boaventura de Sousa (2006), "Uma sociologia das ausências e uma sociologia das emergências”, in B. S. Santos, A gramática do tempo: para uma nova cultura política. Porto: Afrontamento, 87-125.

Spivak, Gayatry C. (1996), "How to Teach a 'Culturally Different' Book”, in Donna Landry; Gerald MacLean (orgs.), The Spivak Reader. New York/London: Routledge, 237-266.

Steiner, George (1996), No Passion Spent: Essays 1978-1996. London: Faber and Faber.

Steiner, George (1998), After Babel: Aspects of Language and Translation. Oxford: Oxford UP.

Subotnik, R. R. (1991), Developing Variations: Style and Ideology in Western Music. Minneapolis/Oxford: University of Minnesota Press.

Taruskin, R. (2000), Defining Russia Musically: Historical and Hermeneutical Essays. Princeton: Princeton UP.

Taruskin, R. (2005), The Oxford History of Western Music. Oxford: Oxford UP. Williams, A. (2001), Constructing Musicology. Aldershot: Ashgate. 